\title{
Polimorfismo do fungo simbionte de formigas cortadeiras submetido à luz ultravioleta
}

\author{
Polymorphism of the cutting ants symbiotic fungus submitted to ultraviolet light
}

\author{
Regina da Silva Borba ${ }^{\mathrm{I} *}$ Alci Enimar Loeck ${ }^{\mathrm{I}}$ Juliana Severo Castelo Branco ${ }^{\mathrm{II}}$ \\ Maurício Marini Kopp ${ }^{\text {II }}$ Antônio Costa de Oliveira ${ }^{\text {II }}$
}

RESUMO

O presente trabalho teve por objetivo verificar o efeito de diferentes períodos de luz ultravioleta sobre a similaridade genética do fungo simbionte de formigas cortadeiras pertencentes às espécies Acromyrmex ambiguus, Acromyrmex crassispinus e Acromyrmex lundi, através da técnica AFLP. Os fungos foram inoculados em meio de cultura Pagnocca e mantidos em câmaras climatizadas à temperatura de $25 \pm 1^{\circ} \mathrm{C}$ e escotofase de $24 \mathrm{~h}$, por um período de 15 dias. Posteriormente, foram expostos à luz ultravioleta por períodos de: $0,5,10,15,20,25$ e 30 minutos. Aos 45 dias após o tratamento, foi realizada a extração do DNA e padronização, realizando-se as reações de PCR por meio de 24 combinações de primers AFLP, das quais quatro foram selecionadas por apresentarem maior polimorfismo e consistência. Os dados moleculares foram transformados em matriz binária $e$ analisados pelo programa estatístico NTSYS v. 2.1. As quatro combinações de primers utilizadas geraram 152 bandas polimórficas. As populações de fungos originárias de diferentes espécies de Acromyrmex apresentaram uma similaridade genética média de $37 \%$, sendo que a indução de mutação através da luz ultravioleta permitiu obter isolados mais dissimilares.

Palavras-chave: AFLP, marcadores moleculares, simbiose.

\section{ABSTRACT}

The present research was aimed at verifing the effect of different periods of ultraviolet light on the development of the symbiont fungus of leaf cutting ants belonging to the species Acromyrmex ambiguus, Acromyrmex crassispinus and Acromyrmex lundi, through the AFLP technique. The fungus were inoculated in Pagnocca's medium and maintained in climatized cameras at $25+1^{\circ} \mathrm{C}$ and 24 hours of darkness, for a period of 15 days. After that, they were exposed to ultraviolet light for 0, 5, 10, 15, 20, 25, and 30 minutes. At 45 days after the treatment, the extraction and standardization of DNA was performed. PCR reactions were tested using 24 AFLP primer combinations, from which four were selected because they presented larger polymorfism and consistence. The molecular data were transformed in binary mattrix and analyzed by the statistical program NTSYS v. 2.1. The four combinations of primers generated 152 polymorfic bands. The fungus populations from different Acromyrmex species presented a medium genetic similarity of the $37 \%$, and the mutations induced by the ultraviolet light allowed to obtain more dissimilar isolates.

Key words: AFLP, molecular markers, symbiosis.

\section{INTRODUÇÃO}

Diferentes espécies de formigas cortadeiras utilizam distintos substratos para cultivar o fungo simbionte, sendo algumas espécies bastante específicas na utilização somente de mono ou dicotiledôneas. Essa condição indica a possibilidade de existir variabilidade genética entre os fungos que cultivam para seu alimento

Tradicionalmente a identificação dos fungos baseia-se na morfologia dos órgãos reprodutivos. Como para o fungo simbionte de formigas cortadeiras não se tem observado esporulação em colônias de fungos ao nível de campo e de laboratório, provavelmente pelo manejo imposto pelas formigas que o cultivam, ou pela perda da capacidade, acredita-se

IDepartamento de Fitossanidade, Universidade Federal de Pelotas (UFPel), Campus Universitário, CP 354, 96010-900, Pelotas, RS, Brasil. E-mail: rsborba@pop.com.br. *Autor para correspondência.

${ }^{\text {II } C e n t r o ~ d e ~ G e n o ̂ m i c a ~ e ~ F i t o m e l h o r a m e n t o, ~ D e p a r t a m e n t o ~ d e ~ F i t o t e c n i a, ~ U F P e l, ~ P e l o t a s, ~ R S, ~ B r a s i l . ~}$ 
que tenham se adaptado às diferentes condições de meio oferecidas pelas formigas, necessitando para isso da ocorrência de variabilidade.

A variabilidade genética é um dos mecanismos de evolução utilizados pelos seres vivos e pode ser alcançada pelos fungos através de mutação ou recombinação gênica. A mutação é o principal mecanismo de variabilidade em fungos. Segundo CAMARGO (1995), vários são os métodos para produzir mutações no DNA. Esses variam desde os métodos físicos e químicos até os métodos mais sofisticados, que envolvem a manipulação direta do DNA. Entre os agentes físicos, a luz ultravioleta, em doses subletais, tem mostrado estimular a esporulação de alguns fungos, porém é altamente letal em alguns casos (STEVENS, 1928).

A caracterização morfológica é tradicionalmente empregada para a identificação de fungos. Entretanto, essa caracterização, embora útil, é bastante limitada devido ao baixo número de caracteres passíveis de serem analisados (FUNGARO, 2000), da alta instabilidade e da dependência da composição do meio utilizado, das condições de incubação e das variações intrínsecas ao microrganismo. Diante disso, as técnicas moleculares baseadas em análise de DNA têm possibilitado o desenvolvimento de métodos rápidos e confiáveis para a caracterização de fungos.

A variabilidade genética entre organismos pode ser determinada através da análise de isoenzimas (NYGAARD et al., 1989). Em fungos, o uso de isoenzimas auxilia na identificação dos isolados que são de difícil separação através de caracteres morfológicos. BOBROWSKI et al. (1998) adaptaram a técnica RAPD para análise do DNA dos diferentes fungos e observaram polimorfismo entre os mesmos.

Os fungos cultivados pelas formigas Attini foram estudados através da técnica de AFLP (Amplified Fragment Length Polymorphism) (VOS et al., 1995; MUELLER et al., 1998). Marcadores AFLP foram usados para comparar o fungo simbionte de ninhos de Acromyrmex octospinosus e Acromyrmex echinatior de uma localidade do Panamá (BOT et al., 2001). Os marcadores AFLP foram eficientes na detecção de isolados fúngicos de diferentes ninhos e forneceram evidências de que existem trocas ocasionais de fungos entre as duas espécies de Acromyrmex (BOT et al., 2001). LOECK et al. (2003) compararam os fungos cultivados por formigas do gênero Acromyrmex em diferentes localidades no Estado do Rio Grande do Sul através da técnica ISSR (Inter Simple Sequence Repeat), sendo que o dendrograma gerado permitiu a formação de quatro grupos, com uma similaridade genética média igual a 0,63 .
O presente trabalho teve por objetivo verificar o efeito de diferentes períodos de exposição à luz ultravioleta sobre o fungo simbionte de formigas cortadeiras das espécies Acromyrmex ambiguus Emery, 1887, Acromyrmex crassispinus Forel, 1909 e Acromyrmex lundi Guerin, 1838, através da técnica AFLP.

\section{MATERIAL E MÉTODOS}

O estudo foi realizado no Laboratório de Mirmecologia do Departamento de Fitossanidade e no Centro de Genômica e Fitomelhoramento do Departamento de Fitotecnia da Faculdade de Agronomia "Eliseu Maciel” (FAEM) da Universidade Federal de Pelotas (UFPel), no ano de 2005. Os isolados do fungo foram retirados da porção mais jovem do jardim e em quantidade suficiente para fazer o isolamento; a coleta foi feita de um ninho de campo de cada uma das espécies, $\boldsymbol{A}$. ambiguus, $\boldsymbol{A}$. crassispinus e A. lundi, que estavam distribuídos ao acaso no município de Capão do Leão, Região Sul do RS.

O cultivo do fungo foi realizado sobre o meio Pagnocca (glucose $10 \mathrm{~g}$, cloreto de sódio 5g, bacto peptona $5 \mathrm{~g}$, extrato de malte $10 \mathrm{~g}$, ágar $15 \mathrm{~g}$, água destilada 1000ml) (PAGNOCCA et al., 1990). A inoculação dos fungos nas placas de Petri foi realizada com o auxílio de um vazador de $4 \mathrm{~mm}$ de diâmetro. $\mathrm{O}$ ensaio foi desenvolvido em câmaras climatizadas do tipo $\mathrm{BOD}$, à temperatura de $25 \pm 1^{\circ} \mathrm{C}$ e escotofase de 24 h, por um período de 15 dias.

Em seguida, foram submetidas à exposição de luz ultravioleta (lâmpada de esterilização germicida, de ondas curtas, $275 \mathrm{~nm}, 30 \mathrm{~W}$ e $90 \mathrm{~cm}$ de comprimento) durante os períodos de: 5, 10, 15, 20, 25 e 30 minutos, sendo a lâmpada mantida a $40 \mathrm{~cm}$ de distância das placas. Cada tratamento contou com 10 repetições para cada espécie de formiga. Decorridos os períodos de exposição, as placas de Petri foram envoltas por um plástico preto por um período de 48 horas para evitar o processo de fotorreativação, mecanismo que reverte diretamente as lesões do DNA induzidas por luz UV, através de exposição à luz branca (KIHARA et al., 2004). Para comparações, foi mantida testemunha (igual número de repetições para cada espécie de formiga) que não sofreu exposição à luz UV. Após os tratamentos, as placas foram recolocadas em BOD (nas mesmas condições de luz e temperatura) e permaneceram mais 45 dias, totalizando 60 dias após a inoculação, quando foi realizada a extração de DNA.

O DNA utilizado nas análises de AFLP foi extraído de acordo com o protocolo modificado descrito por SAGHAI-MAROOF et al. (1984). A quantificação do DNA total foi realizada por eletroforese com gel de 
agarose $1 \%$ corado com brometo de etídeo (SAMBROOK et al., 1989), através da comparação com bandas de concentração conhecida.

A análise de marcadores AFLP foi realizada de acordo com o protocolo descrito por VOS et al. (1995). Foram testadas 24 combinações de iniciadores AFLP, dos quais quatro apresentaram bandas consistentes (C: E-ACT/M-CAG; $\mathrm{C}_{2}$ : E-AGG/M-CTG; $\mathrm{C}_{3}$ : E-AGG/M-CTC; $\mathrm{C}_{4}$ : E-AAG/M-CTC), onde: Ci: iésima combinação de iniciadores; E: EcoRI e M: MseI.

Posteriormente, realizaram-se a digestão do DNA com enzimas de restrição, a ligação de adaptadores específicos aos sítios de restrição, a reação de pré-amplificação e a amplificação seletiva com as quatro combinações de primers citadas anteriormente. O programa de amplificação consistiu de um ciclo inicial de desnaturação a $94^{\circ} \mathrm{C}$ por $30 \mathrm{~s}, 65^{\circ} \mathrm{C}$ por $30 \mathrm{~s}$, para o anelamento dos iniciadores, e $72^{\circ} \mathrm{C}$ por 90 s, para extensão. A temperatura de anelamento foi diminuída em $1^{\circ} \mathrm{C}$, por 11 ciclos, até atingir a temperatura de $54^{\circ} \mathrm{C}$, sendo então realizados mais 23 ciclos com essa temperatura de anelamento.

Para visualizar os fragmentos amplificados e separados eletroforeticamente em gel desnaturante de poliacrilamida (6\%), foi utilizado o protocolo de coloração, à base de nitrato de prata, descrito por CRESTE et al. (2001).

Os dados de presença/ausência de bandas obtidos na análise de AFLP dos 21 genótipos estudados permitiram o cálculo da similaridade genética entre todos os pares de genótipos, com o auxílio do programa computacional NTSYS pc 2.1 (ROHLF, 2000). Para o cálculo da similaridade genética $\left(\mathrm{S}_{\mathrm{ij}}\right)$, foi utilizado o coeficiente de Dice (DICE, 1945), conforme a equação: $\mathrm{S}_{\mathrm{ij}}=2 \mathrm{~N}_{\mathrm{ij}} /\left(\mathrm{N}_{\mathrm{i}}+\mathrm{N}_{\mathrm{i}}\right)$; em que: $\mathrm{N}_{\mathrm{ij}}=$ número de bandas presentes em ambos os genótipos i e j; $\mathrm{N}_{\mathrm{i}}=$ o número de bandas presentes no genótipo $\mathrm{i}$, e $\mathrm{N}_{\mathrm{j}}=$ o número de bandas presentes no genótipo $\mathrm{j}$.

Com base na matriz de similaridade gerada foi construído um dendrograma pelo método de agrupamento da distância média (UPGMA). O ajuste entre a matriz de dissimilaridade e o dendrograma foi estimado pelo coeficiente de correlação cofenética (r) (SOKAL \& ROHLF, 1962), por meio do programa computacional NTSYS pc 2.1 (ROHLF, 2000).

\section{RESULTADOS E DISCUSSÃO}

As quatro combinações de primers utilizadas geraram um total de 152 bandas polimórficas de DNA. O número de bandas geradas por combinação de primers variou de 33 (E-ACT/M-CAG) a 47 (E-AGG/ M-CTG), com uma média de 38 bandas por primer.

Utilizando a similaridade média como ponto de corte, foi possível verificar a formação de quatro grupos distintos: I, II, III e IV (Figura 1). O grupo I representa dois genótipos obtidos de $\boldsymbol{A}$. crassispinus e se mostrou o mais distante dos demais grupos. Já o

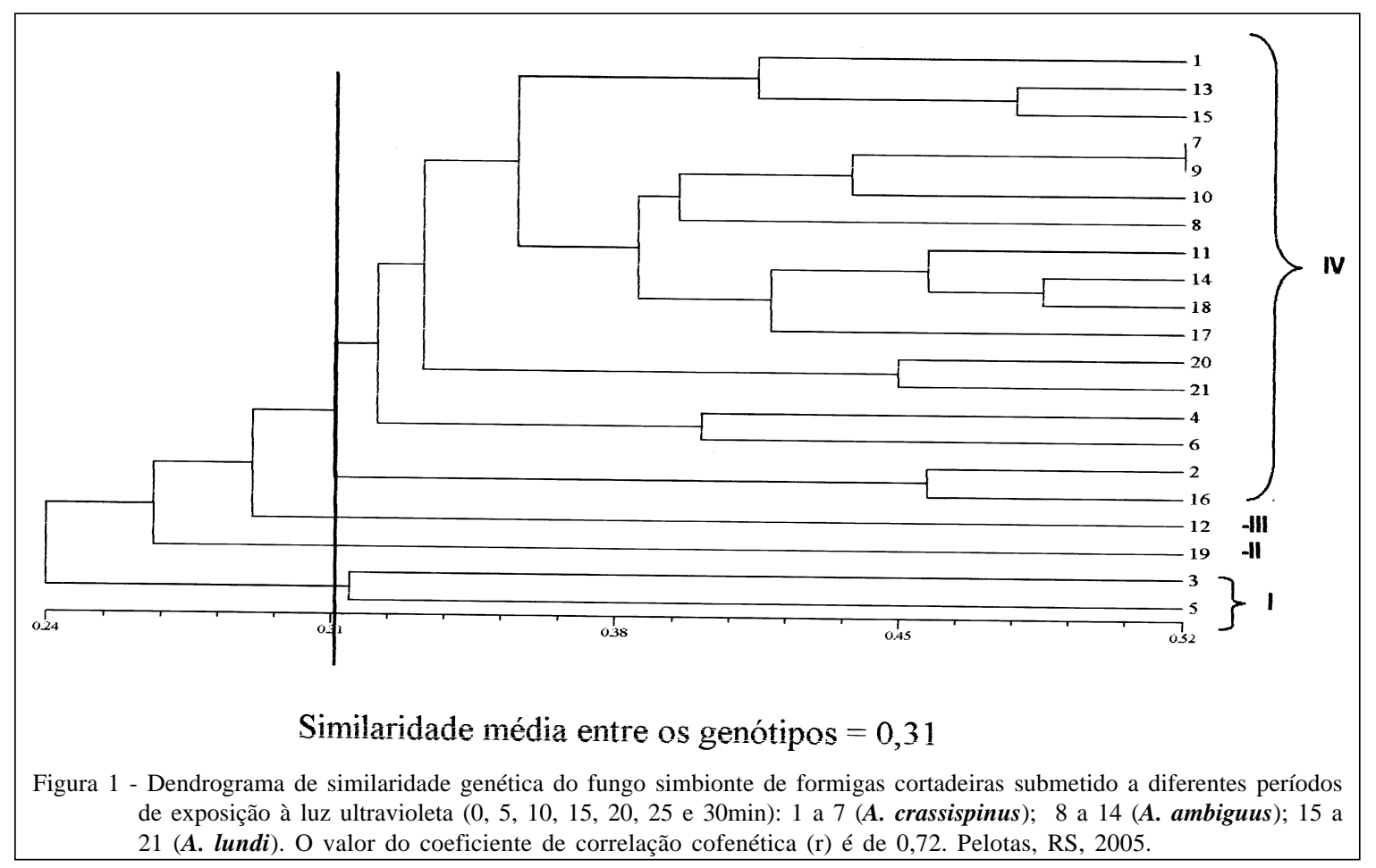

Ciência Rural, v.37, n.5, set-out, 2007. 
grupo IV abrangeu a maioria dos genótipos (inclusive amostras obtidas de $\boldsymbol{A}$. crassispinus). Essa indefinição em relação à genética do fungo dessa espécie já foi constatada no trabalho de LOECK et al. (2003), no qual a similaridade genética do fungo cultivado por $\boldsymbol{A}$. crassispinus coletado no município de Caibaté (Noroeste do RS) foi mais próxima dos fungos cultivados por A. ambiguus (coletados em diferentes regiões) do que os fungos cultivados por $\boldsymbol{A}$. crassispinus no município de Guaíba (Leste do RS).

O grupo III é representado apenas por um dos tratamentos (20 minutos de exposição - número 12 da Figura 1) de A. ambiguus, concordando com AUGUSTIN et al. (1999), que, realizando a identificação de sete espécies de formigas cortadeiras do gênero Acromyrmex através de isoenzimas, observaram que A. ambiguus apresentou a maior dissimilaridade em relação às demais, podendo essa característica se refletir no fungo por ela cultivado.

Os fungos de A. crassispinus e A. ambiguus (sem sofrer irradiação) foram os mais similares (Figura 2), ficando o de $\boldsymbol{A}$. lundi mais distante, concordando com o trabalho de GRÜTZMACHER (2003), que, estudando a variabilidade genética intra e interespecífica em formigas cortadeiras do gênero Acromyrmex de diferentes regiões do Estado do Rio Grande do Sul através das técnicas RAPD e AFLP, observou uma maior proximidade entre as espécies $\boldsymbol{A}$. ambiguus e A. crassispinus, sendo A. striatus mais distante das demais. Esse fato pode estar relacionado também com o hábito dessas espécies, já que $\boldsymbol{A}$. crassispinus e A. ambiguus, geralmente, constroem ninhos mais superficiais, enquanto que os formigueiros de $\boldsymbol{A}$. lundi são subterrâneos (LOECK \& GRÜTZMACHER, 2001). No entanto, a preferência para o forrageamento é a mesma para as três espécies de formigas, que preferem cortar dicotiledôneas (JURUENA \& CACHAPUZ, 1980; FOWLER et al., 1989). GRÜTZMACHER (2003) também concluiu que apenas a técnica AFLP permitiu verificar diferenças intra-específicas, enquanto que ambas as técnicas (RAPD e AFLP) possibilitam a distinção genética interespecificamente.

O aumento do período de exposição à luz ultravioleta não interferiu no polimorfismo entre os genótipos irradiados e a testemunha, sugerindo que a ocorrência de mutação incrementou a variabilidade genética até determinado período de exposição (Figura 3). Pode ser observado que os indivíduos mais dissimilares, i.e., dos grupos I, II e III (Figura 1), foram provenientes de tratamentos entre 10 e 20 minutos de exposição, sugerindo ser esse intervalo o mais apropriado para a maximização da obtenção de variabilidade genética. Segundo HAWKER (1971), a

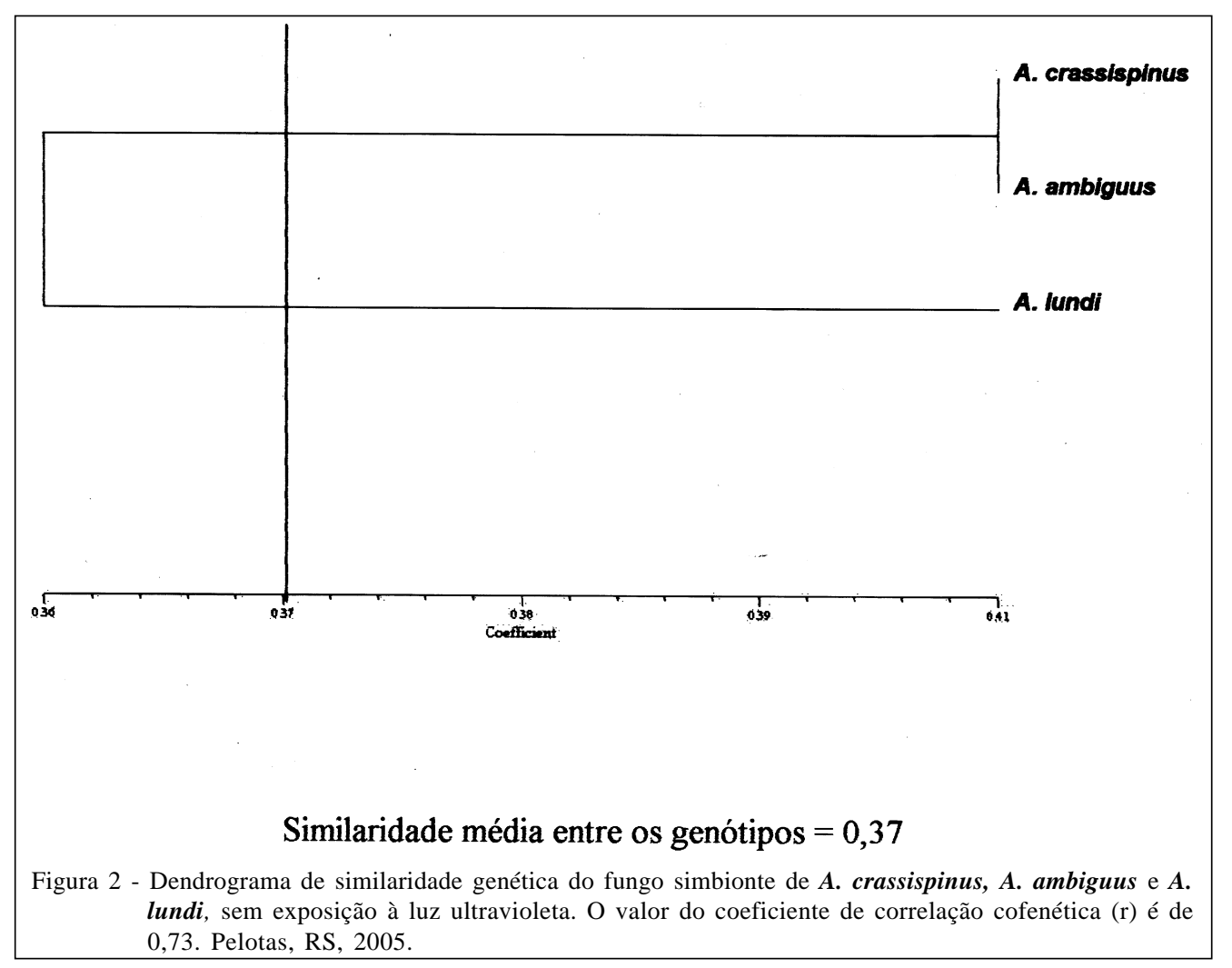

Ciência Rural, v.37, n.5, set-out, 2007. 


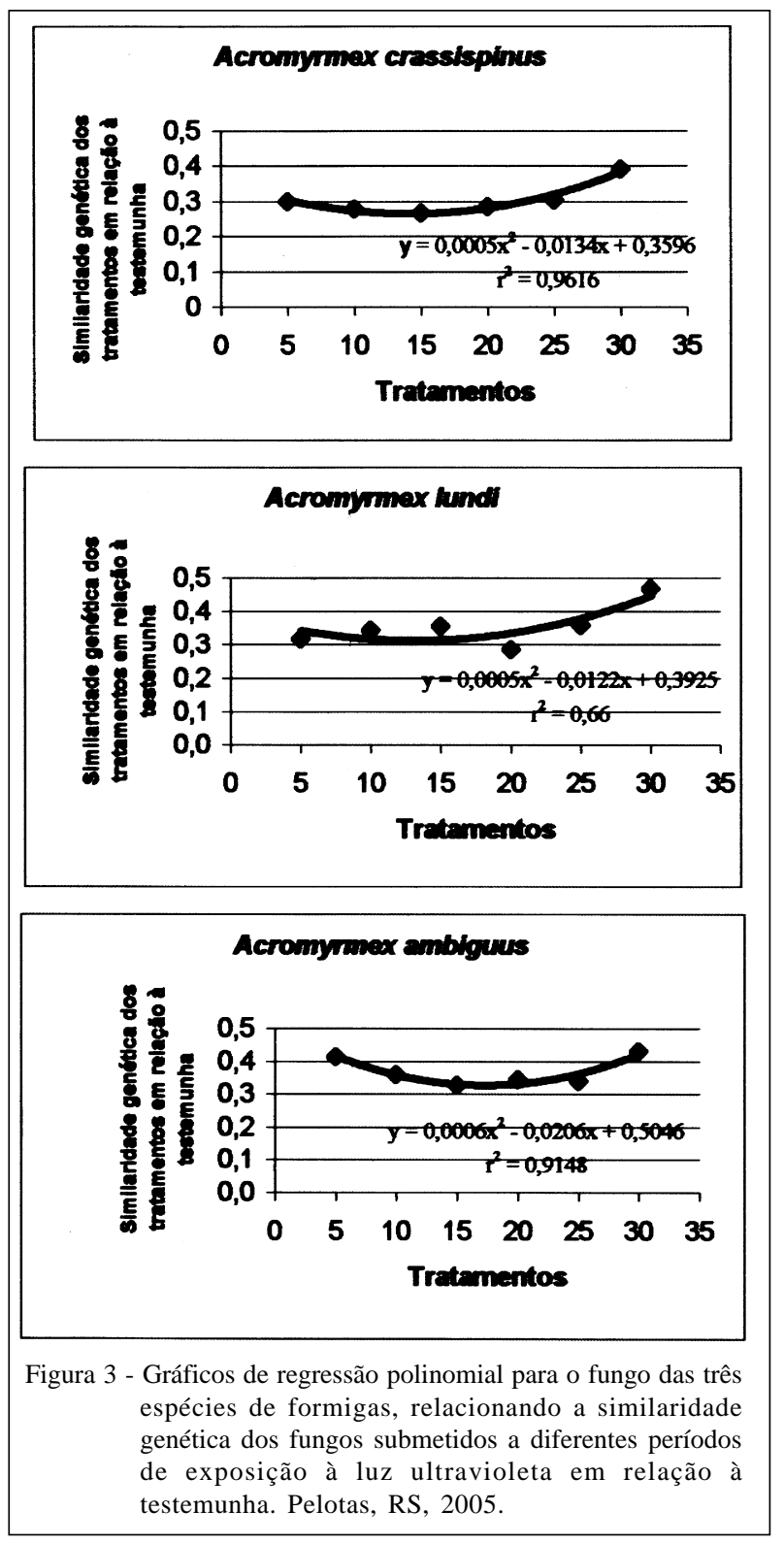

relação entre dose e freqüência de mutação em fungos é, geralmente, não-linear.

Isolados de fungos cultivados por Atta cephalotes de ninhos de duas localidades geograficamente distantes, Panamá e Trinidad, foram analisados por DOHERTY et al. (2003), através da técnica RAPD, os quais observaram considerável variação genética entre os fungos dos diferentes locais, com uma similaridade média de 36\%; já para os isolados oriundos do Panamá e de Trinidad, as similaridades médias foram de 79,6 e 72,1\%, respectivamente. Os autores sugeriram que essas diferenças genéticas resultam de mutação, dispersão, ou ainda, seleção.
A similaridade genética entre o basidiomata encontrado em ninho de campo de Acromyrmex hispidus fallax e o micélio de seu fungo simbionte, isolado e cultivado in vitro, foi confirmada através de RAPD por PAGNOCCA et al. (2001). BRANCHER (1993) analisando variações genotípicas dos fungos de diferentes isolados de Atta sexdens piriventris, Acromyrmex heyeri, A. ambiguus e A. crassispinus, através de eletroforese, observou baixos índices de similaridade genética obtidos entre os isolados provenientes de diferentes espécies de formigas, bem como da mesma espécie, confirmando a alta variabilidade genotípica existente entre os isolados.

Não foi observada uma correlação entre análises morfológicas e genéticas dos isolados (dados não publicados), assim como no trabalho de PERES et al. (2003), que, estudando a variabilidade morfocultural e genética de oito isolados de cada uma das três espécies mais incidentes em frutos de mamão (Colletotrichum gloeosporioides, Phoma caricae-papayae e Fusarium solani), observaram uma alta variabilidade genética entre os isolados de cada espécie fúngica, com alguns desses microorganismos formando grupos divergentes dos demais, não havendo uma relação entre características morfológicas e análises de AFLP.

\section{CONCLUSÕES}

A relação entre os períodos de exposição à luz ultravioleta e a mutação do fungo simbionte das formigas cortadeiras é uma relação polinomial e não-linear. As populações de fungos originárias de diferentes espécies de Acromyrmex apresentam uma similaridade genética média de 0,37.

\section{REFERÊNCIAS}

AUGUSTIN, E. et al. Identificação de formigas cortadeiras do gênero Acromyrmex (Hymenoptera: Formicidae) através de isoenzimas. Revista Brasileira de Agrociência, v.5, n.2, p.217-220, 1999.

BOBROWSKI, V.L. et al. Caracterização do DNA de fungos cultivados por formigas cortadeiras dos gêneros Atta e Acromyrmex através de RAPD. In: CONGRESSO BRASILEIRO DE ENTOMOLOGIA 17., 1998, Rio de Janeiro. Resumos... Rio de Janeiro: Sociedade Entomológica do Brasil, 1998. p.872.

BOT, A.N.M. et al. Partial incompatibility between ants and symbiotic fungi in two sympatric species of Acromyrmex leafcutting ats. Evolution, v.55, p.1980-1991, 2001. 
BRANCHER, N. Avaliação eletroforética e morfológica do fungo cultivado pelas formigas cortadeiras dos gêneros Atta e Acromyrmex. 1993. 58f. Dissertação (Mestrado em Agronomia - Área de Concentração em Fitossanidade) Faculdade de Agronomia “Eliseu Maciel”, UFPel.

CAMARGO, L.E.A. Análise genética da resistência e da patogenicidade. In: BERGAMIN FILHO, A. et al. Manual de fitopatologia. 3.ed. São Paulo: Agronômica Ceres, 1995. v. 1 , p.470-492.

CRESTE, S. et al. Detection of single sequence repeat polymorphism in denaturing polyacrylamide sequencing gels by silver staining. Plant Molecular Biology Reporter, v.19, p.1-8, 2001.

DICE, L.R. Measures of the amount of ecological association between species. Ecology, v.26, n.3, p.297-307, 1945.

DOHERTY, K.R. et al. Random amplified polymorphic DNA markers reveal genetic variation in the symbiotic fungus of leaf-cutting ants. Mycologia, v.95, n.1, p.19-23, 2003.

FOWLER, H.G. et al. A pest is a pest is a pest? The dilemma of neotropical leaf-cutting ants: keystone taxa of natural ecosystems. Envirn Manage, v.13, n.6, p.671-675, 1989.

FUNGARO, M.H.P. PCR na micologia. Biotecnologia Ciência \& Desenvolvimento, v.3, n.14, p.12-16, 2000.

GRÜTZMACHER, D.D. Aspectos morfológicos, moleculares e edafoclimáticos relacionados às formigas cortadeiras no Rio Grande do Sul. 2003. 121f. Tese (Doutorado em Fitossanidade - Área de Concentração Entomologia) - Faculdade de Agronomia “Eliseu Maciel”, UFPel.

HAWKER, L.E. The physiology of reproduction in fungi. New York: Ex-London Library, 1971. 128p.

JURUENA, L.F.; CACHAPUZ, L.M.M. Espécies de formigas cortadeiras ocorrentes no Estado do RS. IPAGRO Informa, Porto Alegre, RS, n.23, p.18-24, 1980.

KIHARA, J. et al. Cloning, functional characterization, and near-ultraviolet radiation-enhanced expression of a photolyase gene (PHR1) from the phytopathogenic fungus Bipolaris oryzae. Current Genetics, v.46, n.1, p.37-46, 2004.

LOECK, A.E.; GRÜTZMACHER, D.D. Ocorrência de formigas cortadeiras nas principais regiões agropecuárias do Estado do Rio Grande do Sul. Pelotas: UFPel, 2001. 147p.
LOECK, A.E. et al. Comparação de fungos cultivados por formigas do gênero Acromyrmex em diferentes localidades no Estado do Rio Grande do Sul através de Marcadores Moleculares tipo ISSR. In: SIMPÓSIO DE MIRMECOLOGIA, 16., 2003, Florianópolis, SC. Anais... Florianópolis: Universidade Federal de Santa Catarina, 2003. p.252 - 253.

MUELLER, U.G. et al. The evolution of agriculture in ants. Science, v.281, p.2034-2038, 1998.

NYGAARD, S.L. et al. Isozyme variability among isolates of Phytophthora megasperma. Phytopathology, v.79, p.773780, 1989.

PAGNOCCA, F.C. et al. Toxicity of sesame extracts to the symbiotic fungus of leaf cutting ants. Bulletin of Entomological Research, v.80, p.349-352, 1990.

PAGNOCCA, F.C. et al. RAPD analysis of the sexual state and sterile mycelium of the fungus cultivated by the leaf-cutting ant Acromyrmex hispidus fallax. Mycological Research, v.105, n.2, p.173-176, 2001.

PERES, A.P. et al. Variabilidade morfocultural e genética de fungos associados à podridão peduncular do mamão. Ciência Agrotécnica, v.27, n.5, p.1053-1062, 2003.

ROHLF, J.F. NTSYS - pc: Numerical taxonomy and multivariate analysis System. Version 2.1. Setauket. NY: Exeter Software, 2000. 38p.

SAGHAI-MAROOF, M.A. et al. Ribosomal DNA spacer length polymorphism in barley: Mendelian inheritance, chromosome location and population dynamics. Proceedings of the National Academy of Sciences of the U.S.A, v.89, n.2, p.1477-1481, 1984.

SAMBROOK, J. et al. Molecular cloning: a laboratory manual. 2.ed. New York: Cold Spring Laboratory, 1989. v.9, p.16-23.

SOKAL, R.R.; ROHLF, F.J. The comparison of dendrograms by objective methods. Taxon, v.11, n.1, p.30-40, 1962.

STEVENS, F.L. Effects of ultra-violet radiation on various fungi. Botanical Gazette, v.86, p.210-225, 1928.

VOS, P. et al. AFLP: a new technique for DNA fingerprinting. Nucleic Acids Research, v.23, p.4407-4414, 1995. 